PressAcademia Procedia

YEAR 2018 VOLUME 7

4th Global Business Research Congress, May 24-25, 2018, Istanbul, Turkey.

\title{
ANALYSIS OF THE RELATIONSHIP BETWEEN HUMAN RESOURCES MANAGEMENT AND INNOVATION IN THE CONTEXT OF TOTAL QUALITY MANAGEMENT PRACTICES: AN EMPIRICAL APPLICATION IN MARMARA REGION
}

\author{
DOI: 10.17261/Pressacademia.2018.870 \\ PAP- V.7-2018(23)-p.144-149
}

Aysel Cetindere Filiz' ${ }^{1}$, Cengiz Duran ${ }^{2}$, Yusuf Ceryan ${ }^{3}$

${ }^{1}$ Ondokuz Mayıs University, Faculty of Economics and Administrative Sciences, Samsun, Turkey aysel.cetindere@omu.edu.tr, ORCID: 0000-0003-1810-5559

2Dumlupınar University, Faculty of Economics and Administrative Sciences, Kütahya, Turkey cduran35@gmail.com, ORCID: 0000-0001-7910-0677

${ }^{3}$ Dumlupınar University, Science Specialist, Kütahya, Turkey.

yusufceryan99@gmail.com, ORCID: 0000-0002-6552-2796

To cite this document

Cetindere Filiz, A., Duran, C., Ceryan, Y. (2018). Analysis of the relationship between human resources management and innovation in the context of total quality management practices: an empirical application in Marmara Region. Press Academia Procedia (PAP), v.7, p.144-149. Permemant link to this document: http://doi.org/10.17261/Pressacademia.2018.870

Copyright: Published by PressAcademia and limited licenced re-use rights only.

\section{ABSTRACT}

Purpose- In this study, it is aimed to investigate the relationship between human resource management and innovation on the basis of total quality management practices.

Methodology- The questionnaire was used as a method of collecting data and information in the study. In the questionnaire form, 28 questions were asked by the employer to evaluate the views and ideas of total quality management (TQM), human resource management (HRM) and innovation. Confirmatory factor analysis, structural equality model, structural validity and reliability analysis and exploratory factor analysis were used to determine the factors that determine the relationship between human resource management and innovation in TQM and to establish the model of the research.

Findings- The total variance explanation ratio of the result of the reliability analysis was calculated as $74,076 \%$ and the general alpha coefficient was 0,976 . Since this ratio is generally $0.80<1.00$ which is considered as the lower limit, the scale is considered as a reliable scale at a high level.

Conclusion- According to the results obtained from the structural equation model; TQM-oriented human resources management and strategic orientation to innovation affects innovation positively and strategic orientation to innovation affects human resources management positively.

Keywords: Total quality management, human resources management, innovation.

JEL Codes: L60, O30, 015

\section{INSAN KAYNAKLARI YÖNETIMi VE YENILIK ARASINDAKi iLIŞKININ TOPLAM KALITE YÖNETIMi UYGULAMALARI KAPSAMINDA INCELENMESI: MARMARA BÖLGESINDE AMPIRIK BIIR UYGULAMA}

\section{ÖZET}

Amaç- Bu çalışmada insan kaynakları yönetimi ile yenilik arasındaki ilişkinin toplam kalite yönetimi uygulamaları temelinde araştırılması amaçlanmıştır.

Yöntem- Çalışmada veri ve bilgi toplama yöntemi olarak anket formundan yararlanılmıştır. Anket formunda işletmelerin toplam kalite yönetimi (TKY), insan kaynakları yönetimi (iKY) ve yenilik konusundaki görüş ve düşüncelerini değerlendirmek için 28 soru yöneltilmiştir. TKY uygulayan işletmelerde IKY ile yenilik ilişkisini ortaya koyan faktörleri belirlemede ve araştırmanın modelini oluşturmada değişkenler arasındaki doğrusal ve doğrusal olmayan ilişkinin değerlendirilmesi için doğrulayıcı faktör analizi, yapısal eşitlik modeli, yapı geçerliliği ve güvenirlik analizi ile açımlayıcı faktör analizleri kullanılmıştır.

Bulgular- Güvenirlik analizi sonucu ölçeğin toplam varyansı açıklama oranı \%74,076 ve genel alfa katsayısı 0,976 olarak hesaplanmıştır. Bu oran genel olarak alt sınır olarak kabul edilen $0,80<1,00$ arasında olduğundan ölçek yüksek derecede güvenilir bir ölçek olarak değerlendirilmiştir.

Sonuç- Yapısal eşitlik modelinden elde edilen sonuçlara göre; TKY odaklı insan kaynakları yönetiminin ve yeniliğe yönelik stratejik oryantasyonun yeniliği olumlu yönde etkilediği, yeniliğe yönelik stratejik oryantasyonun ise TKY odaklı insan kaynakları yönetimini olumlu yönde etkilediği sonuçlarına varılmıştır.

Anahtar Kelimeler: Toplam kalite yönetimi, insan kaynaklari yönetimi, yenilik. JEL Kodları: L60, O30, O15 


\section{GíRiş}

Bir kişi, grup, örgüt ya da toplum için yeni kabul görmekte olan bir fikir meydana getirme süreci olarak kabul edilen yenilik rekabet ortamını ve şartlarını değiştirir. Teknolojik gelişmelerin hızla arttığı ve yoğun rekabet koşullarının ortaya çıkardığı yapı, işletmeleri yenilik yapmaya mecbur kılmıştır. Küreselleşmenin etkisi ile oluşan böyle bir rekabet ortamında yenilik birçok ulus ve işletme için pazarda lider olmanın ana kaynağını oluşturmaktadır. İşletmelerin rekabetçi pazar şartlarında varlıklarını sürdürebilmeleri için yeniliklerin öz kaynaklardan ya da dış kaynaklardan yararlanılarak elde edilmesi zorunlu bir hale gelmiştir. Yenilik, bir işletmenin rakiplerine oranla daha üstün seviyelere gelmesi olanağını sağlayan oldukça önemli bir kavramdır (Higgins,1995: 32-33). Sürekli iyileştirme, sürekli geliştirme gibi yenilik odaklı kavramları temel alan TKY, değişim ve yenilik penceresinden bakıldığında değişimin temel araçlarının başında yer almaktadır. TKY'de değişim asla yeniden yapılanma anlamına gelmemektedir. Çünkü yeniden yapılanmada mevcut sistemi sürdürecek daha güncel bir sistemin kurulması söz konusudur. Ancak TKY'de gelişme; çevre ile uyum, iyinin ve mükemmel olanın genel bir bakış açısı ile aranması, müşteri beklentilerinin karşılanması, artan küresel rekabet gibi faktörler dikkate alınarak sürekli iyileştirmeye gitme çabalarıdır. Bu yaklaşımda başarılı olabilmek için değişime açık olmak ve değişim anlayışında süreklilik göstermek gerekmektedir (Evans, 1997: 82). TKY'nin temelinde yer alan müşteri odakılık prensibi, yenilik kavramı ile yakından ilişkilidir. Bu prensip sayesinde, yenilik çalışmaları müşteri istek ve intiyaçları doğrultusunda şekillenip gerçekleştirilmektedir (Billington, 1998: 7). TKY, yenilik sürecini belirli fonksiyonların yerine getirildiği görevler zinciri olarak değil başarılması gereken bir süreç olarak görmektedir. Yenilik süreci örgütün tümüne yatay olarak yayılmış ve sürecin her aşamasında çeşitli fonksiyonların örtüşerek oluşturduğu, fonksiyonlar arası bir çabayı gerektirir (Benedetto, 1994: 76). TKY müşteri odaklı olan, mükemmellik işlevini bağlı bulunduğu organizasyona adapte etmeye çabalayan, performans ile ilgili problemlere çözüm yolları bulan, takım çalışması, iş başı eğitimleri, iş gören katılımı ve rekabet üstünlüğü gibi ilkeleri başarıyla bünyesinde birleştiren bir yönetim anlayışıdır. Bu ilkeler aynı zamanda insan kaynakları yönetiminin temel fonksiyonları arasında yer almaktadır. TKY uygulamalarında çalışanlar, örgütsel süreçlerde takımın bir parçası olarak görülmektedir (Wilkinson vd., 1995: 2-3). Müşterilerin tatmin düzeylerini kontrol ederek bu düzeyleri en üst seviyelere yükseltmek amacıyla yöneticiler, örgütsel sistemi geliştirmek için planlamalar yaparlar ve bu yöndeki faaliyetleri arttırmaya yönelik çalışmalara giderler. TKY, etkili bir liderlik anlayışı ile insan kaynakları yönetimini geliştirmeyi amaç eder. Bu anlayış ile birlikte TKY anlayışı doğrultusunda hareket eden insan kaynakları yönetimi önemli aşamalar kaydederek sürekli gelişim gösterir (Chen, 1997: 24). Yenilikçi işletmeler için kendi becerilerini ve potansiyelini sürekli geliştiren, her çeşit bilgiye kolayca ulaşabilen ve yaratıcılık yeteneğini sürekli geliştiren insan gücü büyük bir rekabet unsurudur Bu gücün farkında olan ve bu amaçla insan kaynağına yatırım yapan, çalışma koşullarını bu doğrultuda oluşturmaya çalışan işletmelerin sürekli başarı elde etmeleri kaçınılmazdır (Barlay, 2008: 20-21). TKY anlayışını benimsemiş etkin bir insan kaynakları yönetimi birimi bağlı bulunduğu işletmenin yenilik süreçlerine katkı sağlamak adına işe yeni başlayan çalışanlara ve işletmede çalışmaya devam etmekte olan personellere etkili oryantasyon eğitimleri vererek işletmenin verimlilik elde etmesine katkı sağlayabilir. Oryantasyon daha işin başında işi sıkı tutarak çalışanların sürekli gelişmesine katkı sağladığı için insan kaynakları yönetimi tarafından başarıyla sürdürülmesi gereken bir süreçtir.

\section{LITERATÜR ARAŞTIRMASI}

Yapılan literatür çalışmasının sonucunda Flynn (1994), Prajogo ve Sohal (2003) TKY uygulamaları ile teknolojik yenilik kapasitesi arasında pozitif yönde bir ilişkinin olduğunu bulgularken Singh ve Smith (2003) ve Terziovski ve Samson (1998) TKY uygulamalarının inovasyon performansını arttıracağı yönünde herhangi bir bulguya rastlamamışlardır. Perdomo Ortiz vd.(2009) ise İspanya'da faaliyet gösteren toplam 105 endüstri işletmesinde bazı TKY odaklı insan kaynakları yönetimi uygulamalarının teknolojik yenilik kapasitesi üzerinde olumlu etkilerde bulunacağını, özellikle de teknolojik yenilik kapasitesi üzerinde takım çalışmasının doğrudan olumlu bir etkide bulunacağına ilişkin bulgular elde etmişlerdir. Yapılan literatür araştırmasının sonucunda ülkemizde faaliyet gösteren ve çalışma kapsamında ele alınan işletmelerde TKY uygulamaları temelinde yürütülen insan kaynakları yönetimi faaliyetlerinin işletmelerin inovasyon kapasitesi üzerindeki etkileri değerlendirilmiştir.

\section{VERI VE YÖNTEM}

Veri ve bilgi toplama yöntemi olarak anket formu tekniği kullanılmıştır. Hazırlanan anket formu, literatür araştırmasından elde edilen teorik bilgi ve daha önceden yapılmış saha çalışmaları ile Perdomo Ortiz vd. (2009)'in çalışmalarından yararlanılarak tasarlanmıştır. İşletmelerin demografik özelliklerini belirlemek amacıyla 5 soru, TKY, IKY ve Yenilik konusundaki görüş ve düşüncelerini değerlendirmek için ise 28 soru yöneltilmiştir. Anketle TKY uygulayan işletmelerde çalışanların IKY ile yenilik ilişkisi konusundaki fikirlerini değerlendirmek için "Beşli Likert Tipi Ölçek" kullanılmıştır. Araştırmanın evrenini Marmara Bölgesinde beş ilde (İstanbul, Bursa, Kocaeli, Sakarya ve Tekirdağ) faaliyet gösteren farklı sektörlerdeki özel ve kamu işletmeleri oluşturmaktadır. Bu işletmelere anket formu telefonla, e-mail ve yüz yüze yapılan görüşmelerle ulaştırılmıştır. Çalışma, Şubat-Ağustos 2017 tarihleri arasında yapılmıştır. İnsan kaynakları yönetimi ve yenilik ilişkisinin incelenmesi için işletmelerin stratejik açıdan önemli bilgilerine ve karar alma yetkisine sahip kişilere (müdür, müdür yardımcısı, şef, şef yardımcısı) ve diğer personellere (formen, işçi) anket uygulanmış olup 270 adet işletmeden geri dönüş sağlanmıştır. Anketten elde edilen veriler SPPS 18.0 ve AMOS 21.0 paket programları kullanılarak analiz edilmiştir. İşletmelerde insan kaynakları yönetimi ve yenilik arasındaki ilişkinin TKY uygulamaları temelinde araştırılması amacıyla bu ilişkiyi ortaya çıkaran faktörleri belirlemede ve araştırmanın modelini oluşturmada değişkenler arasındaki doğrusal ve doğrusal olmayan ilişkinin değerlendirilmesi için doğrulayıcı faktör analizi, yapısal eşitlik modeli, yapı geçerliliği ve güvenirlik analizi ile açımlayıcı faktör analizleri kullanılmıştır. Bu ilişki içerisindeki farklı koşullu işleyişlerin, insan kaynakları yönetimi ve yenilik arasında var olduğu kabul edilmektedir. Bu bağlamda insan kaynakları yönetiminin bir öğesi olan stratejik oryantasyonun işletmelerde yeniliğe nasıl bir etkide bulunduğunu ve TKY odaklı IKY uygulamalarının da yeniliği nasıl etkilediğini değerlendirmek üzere aşağıda belirtilen hipotezler kurulmuştur:

H1: TKY odaklı IKY yeniliği olumlu yönde etkilemektedir.

H2: Yeniliğe yönelik stratejik oryantasyon yeniliği olumlu yönde etkilemektedir.

H3: Yeniliğe yönelik stratejik oryantasyon TKY odaklı IKY'yi olumlu yönde etkilemektedir. 


\section{BULGULAR}

Ölçeğin yapı geçerliğinin belirlenmesinde açımlayıcı faktör analizi (AFA), güvenirliğinin belirlenmesinde de Cronbach's alfa güvenirlik katsayıları hesaplanmıştır. Ölçeğin faktör analizine uygun olup olmadığını anlamak amacıyla Kaiser-Meyer-Olkin (KMO) ve Bartlett testi yapılmıştır. KMO katsayısı örneklemin büyüklüğünü test etmek için hesaplanmaktadır. Faktör analizinde evrendeki dağılımın normal olması da beklenmektedir. Bu da Bartlett testiyle incelenmektedir. Bu kapsamda KMO testi ölçüm sonucunun 1'e yakın, Bartlett küresellik testi sonucunun da istatistiksel olarak anlamlı olması gerekmektedir.

Cronbach's alfa katsayısının 0-1 arasında değiştiği, değerlendirme kriterlerine göre " $0.00<0.40$ ise ölçek güvenilir değil, $0.40<0.60$ ise ölçek düşük güvenirlikte, $0.60<0.80$ ise ölçek oldukça güvenilir ve $0.80<1.00$ ise ölçek yüksek derecede güvenilir bir ölçek" olarak değerlendirildiği ifade edilmektedir (Tavşancıl, 2005).

Buna göre TKY odaklı IKY uygulamaları, yeniliğe yönelik stratejik oryantasyon ve yenilik ölçeklerine ait KMO ve Bartlett testi sonuçları tablo 1'de gösterildiği gibidir.

Tablo 1: TKY Odaklı iKY Uygulamaları, Yeniliğe Yönelik Stratejik Oryantasyon ve Yenilik Ölçeklerine Ait KMO Örneklem Yeterliliği ve Bartlett Testi Sonuçları

\begin{tabular}{|c|c|c|c|}
\hline & $\begin{array}{c}\text { TKY Odaklı İKY } \\
\text { Uygulamaları Ölçeği }\end{array}$ & $\begin{array}{c}\text { Yeniliğe Yönelik Stratejik } \\
\text { Oryantasyon Ölçeği }\end{array}$ & Yenilik Ölçeği \\
\hline KMO Örneklem Yeterliliği & ,963 & ,794 & ,916 \\
\hline Yaklaşık. Ki-Kare & 5211,373 & 1101,494 & 1101,494 \\
\hline $\mathrm{df}$ & 120 & 21 & 21 \\
\hline Bartlett' in Küresellik Testi & 0,000 & ,000 &, 000 \\
\hline
\end{tabular}

Tablo 1'de belirtilen TKY odaklı IKY uygulamaları, yeniliğe yönelik stratejik oryantasyon ve yenilik ölçeklerine ait KMO örneklem yeterliliği ile Bartlett testi sonuçlarına göre KMO değeri 0,500'den büyük ve Bartlett X2 testi anlamlı bulunmuştur. Buna göre ölçeklerin faktör analizine uygun olduğu görülmektedir.

TKY odaklı IKY uygulamaları, yeniliğe yönelik stratejik oryantasyon ve yenilik ölçeklerine ait maddelerin faktör dağııımı ve güvenirlik analizi sonuçları ise tablo 2'de gösterildiği gibidir.

Tablo 2: TKY Odaklı ikY Uygulamaları, Yeniliğe Yönelik Stratejik Oryantasyon ve Yenilik Ölçeklerine Ait Maddelerin Faktör Dağılımı ve Güvenirlik Analizi Sonuçları

\begin{tabular}{|c|c|c|c|c|c|}
\hline \multirow{9}{*}{ İKY Uygulamaları Ölçeği } & Madde 15 & 3,68 & ,893 & \multirow{9}{*}{74,076} & \multirow{9}{*}{,976 } \\
\hline & Madde 13 & 3,73 & ,892 & & \\
\hline & Madde 14 & 3,72 & ,887 & & \\
\hline & Madde 10 & 3,77 & 879 & & \\
\hline & Madde 11 & 3,59 & ,857 & & \\
\hline & Madde 7 & 3,81 & ,855 & & \\
\hline & Madde 2 & 3,90 & ,849 & & \\
\hline & Madde 9 & 3,79 & ,848 & & \\
\hline & Madde 6 & 3,96 & ,822 & & \\
\hline Yeniliğe Yönelik & Madde 1 & 3,57 & ,905 & \multirow{5}{*}{59,087} & \multirow{5}{*}{,818 } \\
\hline \multirow{5}{*}{$\begin{array}{l}\text { Stratejik Oryantasyon } \\
\text { Ölçeği }\end{array}$} & Madde 4 & 3,70 & ,872 & & \\
\hline & Madde 5 & 3,73 & ,805 & & \\
\hline & Madde 3 & 3,74 & 618 & & \\
\hline & Madde 2 & 3,41 & ,588 & & \\
\hline & Madde 6 & 3,87 & ,832 & \multirow{3}{*}{65,480} & \multirow{3}{*}{911} \\
\hline \multirow[t]{2}{*}{ Yenilik Ölçeği } & Madde 2 & 3,91 & ,830 & & \\
\hline & Madde 4 & 3,89 & ,822 & & \\
\hline
\end{tabular}


Faktör analizi sonuçlarına göre TKY odaklı iKY uygulamaları ölçeğinin faktör yükleri 0,822 ile 0,915 arasında değişen 16 soru ve tek boyuttan oluştuğu belirlenmiștir. Ölçeğin toplam varyansı açıklama oranı \%74,076; güvenirlik katsayısı ise 0,976 'dır. Yeniliğe yönelik stratejik oryantasyon ölçeğinin faktör yükleri 0,588 ile 0,905 arasında değişen 5 soru ve tek boyuttan oluşmaktadır. Ölçeğin toplam varyansı açıklama oranı \%59,087; güvenirlik katsayısı ise $0,818^{\prime}$ dir. Yenilik ölçeğinin faktör yükleri de 0,778 ile 0,832 arasında değişen 7 soru ve tek boyuttan oluşmaktadır. Ölçeğin toplam varyansı açıklama oranı \%65,480; güvenirlik katsayısı ise 0,911 'dir. Buna göre üç ölçeğin de güvenirlik düzeyi yüksektir.

Çalışmada psikolojik sermaye ölçeğinin faktör yapısının doğrulanması ve uyum değerlerinin hesaplanması amacıyla Doğrulayıcı Faktör Analizi (DFA) yapılmıştır. Buna göre elde edilen sonuçlar tablo 3'de gösterildiği gibidir.

Tablo 3: TKY Odaklı iKY Uygulamaları, Yeniliğe Yönelik Stratejik Oryantasyon ve Yenilik Ölçeklerine Ait DFA Analizi Sonuçları

\begin{tabular}{ccc}
\hline Ölçekler & Kabul Edilebilir Uyum Indeksleri & Hesaplanan Uyum Indeksleri \\
\hline \multirow{3}{*}{ TKY Odaklı IKY Uygulamaları Ölçeği } & $\chi 2 / \mathrm{sd}<5$ & 2,741 \\
& $\mathrm{GFI}>0.90$ & 0,904 \\
& $\mathrm{AGFI}>0.90$ & 0,848 \\
& $\mathrm{CFI}>0.90$ & 0,971 \\
Yeniliğe Yönelik Stratejik Oryantasyon Ölçeği & $\mathrm{RMSEA}<0.08$ & 0,080 \\
& $\mathrm{RMR}<0.08$ & 0,033 \\
\hline & $\chi 2 / \mathrm{sd}<5$ & 2,706 \\
& $\mathrm{GFI}>0.90$ & 0,980 \\
& $\mathrm{AGFI}>0.90$ & 0,939 \\
& $\mathrm{CFI}>0.90$ & 0,985 \\
& $\mathrm{RMSEA}<0.08$ & 0,080 \\
& $\mathrm{RMR}<0.08$ & 0,047 \\
\hline & $\chi 2 / \mathrm{sd}<5$ & 2,465 \\
& $\mathrm{GFI}>0.90$ & 0,971 \\
& $\mathrm{AGFI}>0.90$ & 0,932 \\
& $\mathrm{CFI}>0.90$ & 0,984 \\
& $\mathrm{RMSE}<0.08$ & 0,074 \\
\end{tabular}

Tablo 3'den elde edilen sonuçlara göre TKY odaklı IKY uygulamaları ölçeğinin DFA analizinde $\chi 2 / s d$, GFI, CFI, RMSEA ve RMR değerleri kabul edilebilir uyum indekslerini sağlarken; AGFI indeksinin kabul edilebilir uyum indeksine çok yakın olduğu görülmektedir. Buna göre 16 soru ve tek boyuttan oluşan modelin sağlandığı görülmektedir. Yeniliğe yönelik stratejik oryantasyon ölçeği analizine göre de tüm uyum indekslerinin sağlandığı belirlenmiştir. Buna göre 5 sorulu ve tek boyuttan oluşan modelin sağlandığı görülmektedir. Yenilik ölçeğine göre ise analizin tüm uyum indekslerini sağlaması nedeniyle 7 soru ve tek boyuttan oluşan modelin geçerliliği kabul edilmektedir.

Tablo 4'de TKY odaklı IKY uygulamalarının ve yeniliğe yönelik stratejik oryantasyonun yeniliğe etkisi ile yeniliğe yönelik stratejik oryantasyonun IKY uygulamalarına etkisini incelemek amacıyla kurulan Yapısal Eşitlik Modelinden (YEM) elde edilen sonuçlar görülmektedir.

Tablo 4: YEM Analizinin Sonuçları

\begin{tabular}{ccccccc}
\hline Etkilenen & & Etkileyen & Tahmin (B) & sh & T & p \\
\hline Yenilik & $<---$ & Insan Kaynakları Yönetimi &, 813 &, 060 & 13,524 & $* * *$ \\
\hline Yenilik & $<---$ & Yeniliğe Yönelik Stratejik Oryantasyon &, 773 &, 057 & 13,503 \\
\hline IKY & $<---$ & Yeniliğe Yönelik Stratejik Oryantasyon &, 893 &, 054 & 16,490 \\
\hline
\end{tabular}

Tablo 4'den elde edilen sonuçlara göre iKY yeniliği olumlu yönde $(p<0,05 B=0,813)$; yeniliğe yönelik stratejik oryantasyon yeniliği olumlu yönde ( $p<0,05 B=0,773$ ); yeniliğe yönelik stratejik oryantasyonun insan kaynakları yönetimini de olumlu yönde ( $p<0,05 B=0,893$ ) etkilediği bulgulanmıştır.

Tablo 5' de TKY odaklı IKY uygulamalarının ve yeniliğe yönelik stratejik oryantasyonun yeniliği etkileme durumu ile yeniliğe yönelik stratejik oryantasyonun TKY odaklı IKY uygulamalarını etkileme durumlarının incelenmesi amacıyla yapılan regresyon analizi sonuçları görülmektedir. 
Tablo 5: Modele Ait Regresyon Analizi Sonuçları

\begin{tabular}{|c|c|c|c|c|c|c|c|}
\hline Bağımlı Değişken & Bağımsız Değişken & $\mathbf{F}$ & $p$ & B & $t$ & $\mathbf{P}$ & R2 \\
\hline \multirow[b]{2}{*}{ Yenilik } & Sabit & & & 5,289 & 10,061 & ,000 & \\
\hline & $\begin{array}{c}\text { TKY Odaklı İnsan } \\
\text { Kaynakları Yönetimi } \\
\text { Uygulamaları }\end{array}$ & 1797,447 & ,000 & ,357 & 42,396 & , 000 & 0,870 \\
\hline \multirow[b]{2}{*}{ Yenilik } & Sabit & & & 6,127 & 7,546 & ,000 & \\
\hline & $\begin{array}{c}\text { Yeniliğe Yönelik } \\
\text { Stratejik } \\
\text { Oryantasyon } \\
\end{array}$ & 692,18706 & ,000 & 1,146 & 26,309 & 000 & 0,721 \\
\hline \multirow[b]{2}{*}{$\begin{array}{c}\text { TKY Odaklı İnsan } \\
\text { Kaynakları Yönetimi }\end{array}$} & Sabit & & & 2,551 & 1,508 & 133 & \\
\hline & $\begin{array}{c}\text { Yeniliğe Yönelik Stratejik } \\
\text { Oryantasyon }\end{array}$ & 1242,3459 & ,000 & 3,197 & 35,247 & ,000 & 0,823 \\
\hline
\end{tabular}

Tablo 5'den elde edilen verilere göre TKY odaklı İKY uygulamalarının, yeniliğe yönelik stratejik oryantasyonun ve yeniliğe yönelik stratejik oryantasyonun TKY odaklı IKY uygulamalarını etkileme durumunun incelenmesi amacıyla yapılan regresyon analizi istatistiksel olarak anlamlı bulunmuştur $(p<0,05)$. Modeldeki katsayılar incelendiğinde TKY odaklı IKY uygulamalarının yeniliği olumlu yönde etkilediği belirlenmiştir $(B=, 357 p<0,05)$. Yenilikteki değişimin \%87'si TKY odaklı iKY uygulamaları tarafından açıklanmaktadır. Yeniliğe yönelik stratejik oryantasyon için modeldeki katsayılar incelendiğinde yeniliğe yönelik stratejik oryantasyonun yeniliği olumlu yönde etkilediği belirlenmiştir $(B=1,146 p<0,05)$. Yenilikteki değişimin \%72'si yeniliğe yönelik stratejik oryantasyon tarafından açılanmaktadır. Yeniliğe yönelik stratejik oryantasyonun TKY odaklı IKY uygulamalarını etkileme düzeylerini belirlemek için yapılan regresyon analizi sonucuna göre modeldeki katsayılar incelendiğinde yeniliğe yönelik stratejik oryantasyonun TKY odaklı IKY uygulamalarını olumlu yönde etkilediği belirlenmiştir $(B=3,197 ; p<0,05)$. Buna göre TKY odaklı IKY uygulamalarındaki değişimin \%82'si yeniliğe yönelik stratejik oryantasyon tarafından açıklanmaktadır.

\section{SONUÇ}

Toplam kalite yönetimi organizasyonların takımlar halinde sistematik bir şekilde çalışması gerektiğini ve kalite sağlama çabalarının işçiden üst yönetime kadar herkesin işi olduğu görüşünü savunan, günün gereklerine göre kendini sürekli yenileyen ve geliştiren süreçler bütünüdür. Başarılı bir şekilde yönetilmesi gereken yenilik süreci ise yeniliklere açık ve yenilik uygulamaya istekli donanımlı bireylerin işletmeye kazandırıması ile mümkün olmaktadır. Toplam kalite yönetimi anlayışını benimsemiş etkin bir insan kaynakları yönetimi birimi yenilik gerçekleştirme süreçlerinde de etkili bir rol oynayacaktır. Toplam kalite yönetimini uygulayan işletmelerde insan kaynakları yönetimi ve yenilik arasındaki ilişkinin incelenmesi için yapılan bu araştırmadan elde edilen YEM sonuçlarına göre; araştırma modelinde yer alan $\mathrm{H} 1$, H2 ve H3 hipotezleri kabul edilmiştir. Buna göre:

•TKY odaklı IKY yeniliği olumlu yönde etkilemektedir.

•Yeniliğe yönelik stratejik oryantasyon yeniliği olumlu yönde etkilemektedir.

-Yeniliğe yönelik stratejik oryantasyon TKY odaklı IKY'yi olumlu yönde etkilemektedir sonuçlarına ulaşılmış ve hipotezler doğrulanmıştır.

Bilgiye kolay ulaşabilen, kendini sürekli yenileyen, teknolojik gelişmelere ilgi duyan ve bu teknolojileri kullanabilen insan kaynağının işletmelere kazandırılması işletmeler için stratejik önem arz etmektedir. Nitelikli adayların işe seçilmesi, işe alıştırılması ve işte tutundurulması faaliyetleri ile adil ücret sistemlerinin uygulanması gibi birçok işlevsel faaliyet insan kaynakları yönetiminin temel görevlerini oluşturur. Çalışanların moral ve motivasyonunu sağlayarak verimliliği arttırıcı çalışmalar yapmak da yine insan kaynakları yönetiminin temel amaçlarından biridir. Toplam Kalite Yönetimi anlayışıla müşteriyi öncelikleyen, takım çalışmasını destekleyen, eğitime önem veren ve sürekli gelişmeyi temel felsefe olarak benimseyen işletmelerde insan kaynakları yönetiminin etkinliği daha da artacak ve böylece işletmeler çalışanlarıyla birlikte yeniliklere daha açık bir yapı kazanarak rekabet gücünü arttırabilecektir.

\section{KAYNAKLAR}

Barlay, Ö. (2008). Türk holdinglerinde yenilik sürecinde insan kaynakları yönetimi faaliyetlerini değerlendirme araştırması. Dönem projesi. Ankara Üniversitesi Sosyal Bilimler Enstitüsü, Ankara.

Benedetto, C. A. (1994). Defining markets and users for new technologies. Edited by Souder Wm. E. ve Sherman Daniel J., Managing New Technology Development, McGrawHill Inc., New York.

Billington, J. (1998). Customer driven innovation. Harvard Management Update, Vol.3, No.7, pp.7-9.

Chen, W. H. (1997). The human side of total quality management in Taiwan: leadership and human resource management. International Journal of Quality \& Reliability Management, Vol.14, No:1, pp. 24-45.

Evans, J. R. (1997). Production/operations management: quality, performance and value. WestPublishing, Mineapolis.

Flynn, B. B. (1994). The relationship between quality management practices, infrastructure and fast product innovation. Benchmarking for Quality Management \& Technology, Vol.1, No.1, pp.48-64. 
Higgins, J. M. (1995). Innovation core competence. Planning Review, Nov./Dec., pp.32-36.

Perdomo-Ortiz, J., González-Benito, J., Galende, J. (2009). The intervening effect of business innovation capability on the relationship between total quality management and technological innovation. International Journal of Production Research, Vol.47, No.18, pp.50875107.

Prajogo, D. I., Sohal, A. S. (2003). The relationship between TQM practices, quality performance, and innovation performance: an empirical examination. International Journal of Quality and Reliability Management, Vol.20, No.8, pp. 901-918.

Singh, P. J., Smith, A. J. R. (2003). Relationship between TQM and innovation: an empirical study. Journal of Manufacturing Technology Management, Vol. 15, pp. 394-401.

Tavşancıl, E. (2005). Tutumların ölçülmesi ve SPSS ile veri analizi. Nobel Yayıncılık, Ankara.

Terziovski, M., Samson, D. (1998). The link between total quality management practice and organizational performance. International Journal of Quality and Reliability Management, Vol.16, No.3, pp. 226-237.

Wilkinson, A. (1995). Towards human resource management? A case study from banking. Research and Practice in Human Resource Management, Vol.3, No.1, pp.97-115. 